\title{
Disability Care in Nigeria: The need for professional advocacy
}

\author{
Amusat, N. \\ Stroke and Geriatric Empowerment Program, Two Hills Health Centre, Two Hills, Alberta, Canada \\ Email:sepet69@hotmail.com
}

\begin{abstract}
SUMMARY
Physical therapists (PTs) as rehabilitation experts, have a unique role to play in fostering independence for people with disability and reducing human disability levels in Nigeria. Access to rehabilitation for people with disability is inadequate, with the attendant economic and social implications if the status quo is maintained. Changes are required in how people perceive disability and in legislation, through policy direction and implementation, to achieve the goal of equal opportunities for people with disability. The current dispensation indicates that physical therapists may have been complacent about the advocacy role that they need to play to bring about a positive change for people with disability. Improved advocacy by physical therapists and their organizations at all levels of the society will directly impact people with disability and indirectly improve the professional standing of physical therapists (PTs).
\end{abstract}

KEY WORDS: disability, advocacy, physical therapy, legislation

\section{INTRODUCTION}

Physical therapy as a profession is concerned with identifying and maximizing the quality of life and movement potential within the spheres of promotion, prevention, treatment/intervention, habilitation and rehabilitation (World Confederation of Physical Therapy (WCPT), 1999). The World Confederation of Physical Therapy (2007) released a position statement designating physical therapists as exercise experts across lifespan. The therapeutic exercises provided by physical therapists have been proven to be effective for a wide range of conditions and for all age groups (Australia Physiotherapy Association, 2006).

Despite the expertise in therapeutic exercises and the available evidence of effectiveness, many people continue to live with physical disabilities across the globe, especially in Africa. The vicious cycle of disability and poverty has been recognized, which led the United Nations to promulgate rules for equal opportunities for people with disability, with rehabilitation as one of the tenets for achieving an optimal level of independence (United Nations, 1993). However, despite many disability initiatives, accessibility to rehabilitation is far from being achieved for people with disability in Africa in general, and Nigeria in particular. The poor perception of disability and people living with it has fuelled the lacklustre attitude of government in terms of policy direction and action. This is unfortunate because the extent to which a society provides and indeed funds rehabilitation is probably a good measure of how much interest it has, and importance it attaches to the well-being of its citizens (Poulis, 2007). Physical therapists in Nigeria have a big role to play in changing the status quo for disability and care of people with disability. The perception of people with disability has to change, not only within their families and society, but also among the policy makers. An unprejudiced view of people with disability backed with adequate policy directions that promote prompt access to rehabilitation services will go a long way to improve the public perception of what we do as PTs. The rest of this article will discuss the issue of disability and the advocacy role of physical therapists.

\section{Disability}

Disability is both a cause and a consequence of poverty. There is a strong relationship between disability and poverty with a cyclical tendency - poverty makes people more vulnerable to disability and disability reinforces and deepens poverty. Disability is an important factor, along with gender, race and caste, that interacts to impoverish people and keep them poor (Mji et al, 2009). People with disability are often excluded from the mainstream of society, and hence, may not contribute to the development of the society at all or optimally. It is increasingly being recognized that bringing people with disabilities into the development mainstream will have a significant effect in any plan to cut poverty in the developing world 
(Wolfensohn, 2002). This is especially true, given that disability affects not only the individual, but also the family and the larger society. In Africa, previous efforts to put disability in the forefront of the development agenda has not yielded all the expected results. This was as a result of poor resources, blamed partly on the lack of commitment on the part of governments (Mji et al, 2009).

Having access to health and rehabilitation services is a precondition to equal opportunities, as outlined in the United Nations (UN) standard rules for equal opportunities (United Nations, 1993), and an essential component of being a valued and productive member of the society. As a result of the UN standard rules on the equalization of opportunities for people with disability, some countries have tried to develop strategies to address disability in the process of overall development strategies (South Africa Integrated National Disability (SAIND) White Paper, 1997). South Africa's key policy areas included notably, prevention, health care, rehabilitation and research. Policy objectives, strategies and mechanisms for each area were developed. The strategy identified the need for legislative scrutiny which may lead to new legislation or amendments of existing ones. However, even where government commitment and the policy environment are favourable, majority of the people with disability may not experience significant changes in quality of life, access to equal rights and level of community integration. Disability, therefore, continues to be a concern, leading to many international initiatives like those by the United Nations Educational, Scientific and Cultural Organization (UNESCO), International Labour Organization (ILO) and the World Health Organization (WHO). Also, the theme for the forthcoming World Health Report (2009) will be disability (Mji et al, 2009). The success of the multiple international initiatives on disability will be influenced by many factors. Of particular importance is an evidence-based policy decision, followed by practical action by all stakeholders.

\section{Disability in Nigeria}

Disability is very common worldwide. The World Health Organization (WHO) estimated that about 500 million people live with disability worldwide, with about $75 \%$ living in the developing countries (Mickailakis, 1997; Lang and Upah, 2008). In Nigeria, WHO estimates put the number of people with disability at 19 million or approximately $20 \%$ of the country's population (Lang and Upah, 2008). There are no credible and robust statistics in Nigeria about most things, including disability. There is therefore a big knowledge gap that needs to be bridged.
The Nigerian government supported the UN standard rules on the equalization of opportunities for people with disability. There was also a decree promulgated in 1993 to enhance the social and societal position of people with disability. Nigerians living with disability are no better off when compared with others living in other parts of the developing world, in terms of the challenges they face they are poor, marginalized and excluded (The Guardian, April 12, 2009; Lang and Upah, 2008). Despite the declaration of full participation in the disability agenda of the United Nations by the Nigerian government, Nigerians with disabilities are still faced with these challenges (The Guardian, April 12, 2009; Michailakis, 1997).

A recent review of disability issues in Nigeria identified many factors why the disability agenda continues to suffer. Notable among them were: the absence of disability discrimination laws, lack of social protection, poor understanding of disability issues by the public, and poor access to rehabilitation services. The report recommended, among others, the collection of robust and reliable data, and advocacy for the passage of the disability bill into law (Lang and Upal, 2008).

\section{Advocacy}

Advocacy is a legal term that has a precise meaning - it is the process of pleading for another person in court (Wheeler, 2000). An expanded definition states that advocacy is stating a case to influence decisions, getting better services, being treated equally, being included, being protected from abuse, redressing the balance of power and becoming aware of and exercising rights (Jugessur and Iles, 2009). Many types of advocacy have been identified, which include: independent professional, service professional, family, self, citizen, peer, and collective advocacy. In practice, it may actually be difficult to distinguish one type from the other (Wheeler, 2000). The importance of advocacy in health and social care has relevance to issues of poverty, disability, minority status and mental health (Jugessur and Iles, 2009). To the professionals involved in advocacy, there are some advantages - entitlement to take part in clinical decision-making and increased professional standing (Schwartz, 2002). There has been a raging controversy in nursing as to whether advocacy is part of the professional responsibility of nurses (Jugessur and Iles, 2009; Wheeler, 2000). The arguments have bordered on the ability to advocate, and at the same time, protect the autonomy of the client in an environment where there is an imbalance of power in favour of the health care professionals (Schwartz, 2002). In summary, advocates were expected to ensure that: the patient had enough 
information to exercise autonomy; legal and moral rights are respected; and health care resources allow appropriate quality and quantity of care (Hyland, 2002). Advocacy has been discussed extensively in nursing literature, but is there a role for advocacy in the physical therapy profession?

\section{Is Advocacy Part of Professional Responsibility in Physical Therapy?}

Advocacy has not been discussed to the same extent in physical therapy as in nursing. It has been mentioned in relation to physical therapy practice (Malone, 2001; Ward, 2007), however, the paucity of literature on advocacy in physical therapy does not mean that advocacy is not pursued by physical therapists. The advocacy role for physical therapists is emphasized in the code of conduct declaration for the profession (code of ethics) (WCPT, 1995).

Professional advocacy in physical therapy, could be broadly divided into two. The first is empowering clients to self-advocate through the provision of information and support, while the second type involves influencing a third party on behalf of clients. The appendix to the ethical principles of the WCPT describes the two types of advocacy that physical therapists can provide: supporting client advocates (i.e. self-advocacy), and advocating on behalf of clients. While we continue to provide relevant information to enable our clients make autonomous decisions, the physical therapy profession in Nigeria needs to do more to influence decision makers so that a favourable environment can be provided to enhance accessibility and hence, maximize the benefits derived from therapeutic interventions.

Professional advocacy has its roots in the legal profession. It is also referred to as legal advocacy. Legal advocacy is the act of putting one's case in a most persuasive manner, involving presentation of relevant facts and principles of law, so arranged as to have maximum impact in the minds of the audience (Grace, cited in Jugessur and Iles, 2009, p.188). Leaning heavily on this legal advocacy definition, professional advocacy in physical therapy would involve presentation of relevant health facts garnered through research, designed to influence policy directions in a way to allow appropriate quantity and quality of physical therapy care to satisfy societal needs.

In the heart of our advocacy, there are a number of things on which we must focus. These include the following:

a. Improve accessibility to rehabilitation services

b. Have a sound research agenda that is robust for gathering data, its peer review process, dissemination of research results and ability to translate research to evidence-based information needed to influence policy.

c. Provide coordinated, coherent and consistent professional strategic direction and a lobbying agenda that focuses on building a strong internal and external alliance to be able to influence policy directions, implementation and enforcement at all levels of government.

\section{Accessibility to Rehabilitation Services}

Accessibility of services is essential if the goal of fostering functional independence is to be achieved in people with disability. Accessibility to rehabilitation services is currently very poor in many developing countries (Lang and Upah, 2008; Mji et al, 2009). This shows the importance the society attaches to people with disability (Poulis, 2007). Rehabilitation is usually considered as a sort of optional extra to the more 'important' medical care. The fact that it is through rehabilitation that functional independence is restored, makes it liberating to people with disability and indeed important to the society that cares to have a productive citizenry. Many of the people with disability do not have the funds to pay for rehabilitation services. In addition, therapists are not available in enough numbers and geographical spread to provide the required access throughout the country. Why should cost of rehabilitation services be such a difficult thing for people with disability? The Nigerians With Disability Decree of 1993 stipulated that: "disabled persons shall be provided in all public health institutions free medical and health services". This law is definitely for the archives and is not working. It is the duty of the members of our profession to make this part of our law work. However, before we can pursue a meaningful advocacy push, we need convincing numbers to show the accessibility gaps that currently exist in our society.

The reasons for the accessibility issues need to be documented in a systematic way, from the perspectives of the people with disability and their care givers, professionals and organizations working to alleviate the conditions of people with disability. For example, the absence of practice standards along the continuum of care for stroke patients and the inability to provide adequate rehabilitation services through acute, sub-acute, rehabilitation units, and to the community, are major issues of poor accessibility of services. It is a well known fact that stroke patients who receive rehabilitation in a stroke unit do better (Teasell et al, 2009). But, do we have 
well-staffed stroke units in all the geographical zones of the country? There are a lot of issues that can be brought forward and for which a case can be made. Physical therapy, being the largest of the rehabilitation professions in Nigeria, is well positioned to assist the nation in her quest for an economic breakthrough. Productivity is linked to functional capacity; so, how can the country achieve this when about $20 \%$ of its citizens are disabled?

\section{Research Direction}

The disability agenda in developing countries has not yielded adequate results partly due to the paucity of statistical studies to gather reliable data, poor dissemination of research results, and inability to use the available data optimally. Evidence-based practice emphasizes the importance of assessment, planning, delivery, and evaluation of services based on sound research results (Parahoo, 2000). Decisions about policy, services and intervention, based on firm evidence will result in optimal gains for people with disability (Mmatli, 2009; Parahoo, 2000). The use of different forms of research to achieve this aim has been advocated. Mmatli (2009) made a strong case for the ability of qualitative research to make the suppressed voices of people with disability, heard. He also recognized that policy makers tend to prefer quantitative research because of its systematic, standardized and easy-to-read format. The use of research, especially in influencing overall policy directions, and in particular, as it relates to disability, has been poor. Some reasons given for this stance in Africa include: negative attitude towards disability, inaccessibility of research reports, and the view by most practitioners that research has limited relevance to practice (Mmatli, 2009).

Our research agenda needs to focus on the following:

1. Physical therapy needs strong research education and research partnership. The establishment of research-based doctorate programmes in some of the universities is a step in the right direction. This will enhance research capacity in the near future. The universities with these programmes need to align the curriculum to meet the standards obtainable in most developed countries.

2. Strong research direction. Research direction has not been aligned adequately with the needs of the society. The profession needs to know the things that require urgent attention in the area of physical therapy and rehabilitation. The ability to do a meaningful environmental scan and address these needs in a timely fashion will position us well to advocate for changes. Examples may include obesity, cardiovascular health (prevention of strokes and cardiac attacks), automobile accidents and absence of meaningful insurance coverage, injury at work, and absence of health and rehabilitation care coverage and compensation etc.

Physical therapy academics and clinicians need to work together to develop a meaningful and more beneficial strategic direction. There are questions begging for answers in many spheres of PT practice. Answering these questions systematically, with the increasing level of qualified researchers that we now have is a must-do task. For example, there are a number of questions in stroke rehabilitation that we need answers for in no particular order:

- What is the incidence and prevalence of stroke in Nigeria?

- How many stroke patients visit a hospital after stroke?

- What is the mortality rate after acute stroke?

- What is the mortality rate among stroke patients after discharge from in-patient admission?

- How many stroke patients get access to physical therapists in Nigeria (urban versus rural)?

- What is the physical therapy workforce like vis-àvis accessibility of rehabilitation to stroke clients?

- What is the distribution of PTs in Nigeria in urban and rural areas?

- What is the referral rate for physical therapy from in-patient units before discharge from hospital?

- What is the knowledge-base of the medical doctors about physical therapy (after all, they have to refer the stroke patients for rehabilitation)?

- How many professionals collaborate in the care of a stroke patient?

- How many stroke patients get rehabilitation after discharge from hospital?

- What are the characteristics of patients that sought rehabilitation after stroke?

- What is the satisfaction rate for rehabilitation care after stroke?

- What informs why stroke patients prefer to attend traditional healers and spiritual enclaves when looking for rehabilitative care?

- If patients left physical therapy for other 'healing arenas' instead of continuing rehabilitation, what informed their decision?

- Are stroke patients capable of integrating into their community after discharge? 
- What is the psychological impact of role reversal in the lives of stroke patients?

- What is the suicide rate among people with stroke?

- What is the physical complication rate after stroke, with or without rehabilitation?

- What about environmental barriers and availability of equipments?

- What is the average cost of PT and what are the difficulties people face to pay for them?

- What is the level of understanding of stroke and its risk factors among Nigerians - urban and rural dwellers?

- How do stroke patients and their families view the role of physical therapy in their functional recovery after stroke?

There are thousands of questions begging for answers in all spheres of physical therapy practice in Nigeria. If we do not have the right questions, we may not be able to provide the right answers. Providing the most appropriate answers will have to take into account geographical and ethnic/tribal beliefs and norms. Therefore, to answer some of these questions, we need a high level of research ability and team spirit. Some of the questions are better answered by collaborating with other professionals in the health care arena.

3. Research collaborations and alliances. Health teams in developed countries have moved from multi- disciplinary to interdisciplinary formations, and are now trying to evolve into trans-disciplinary teams. There are challenges in making a team work properly, but the end result could benefit patients significantly. The physical therapy profession in Nigeria is not only young, but also has a lot of challenges that would not be overcome by working in isolation. As patients' clinical issues are best addressed by a health care team, so are the complex research issues best addressed by a team.

Teamwork within and outside the profession is urgently needed. How many times have there been interuniversity research collaboration among PT academics/ clinicians? More inter-university and inter-geographical collaboration is needed to study the complex needs of the population the physical therapists serve in Nigeria. We also need to go outside the bounds of the PT profession and collaborate with doctors, to find answers to some of these questions. Inter-professional trust will be built this way and breakthroughs may be achieved on some other issues.
Clinicians should also be encouraged to participate in research along with their academic counterparts.

Partnerships with clinicians and other health professional are bound to yield the greatest benefits. Some of the immediate benefits may be the easy integration of research findings into best practice standards or clinical practice guidelines. Many clinical guidelines trail the evidence they convey by many years. Many nationwide research endeavours will be hard to implement because we do not currently have academic programmes in all the regions of the country. But clinicians are available in most places that we could partner with to make for an all inclusive data collection strategy. We should remembered that clinicians are better placed to identify the issues that are of greatest importance to clinical practice, while the research academics have the training to turn these questions into viable research.

Research funding is also very poor in Nigeria. Building alliances and collaboration with donor agencies will help in accessing funds for research. Also, there is the need to foster alliances with universities abroad with a strong research agenda on issues that affect African countries. These alliances would not only increase capacity, it would enhance credibility of results and availability of funding from donor agencies. Research efforts will continue to be rudimentary, at best for a long time to come, unless we form partnerships with universities with strong, but similar research direction as ours and with renowned researchers worldwide. These renowned universities and researchers have enormous leverage to attract grants for research. An urgent scan of the Nigerian landscape is required for nongovernmental groups and international agencies working on disability issues (see Appendix). Nothing stops us from initiating partnerships directly with agencies outside Nigeria (in and outside Africa) for our research ideas. This is becoming increasingly easy with the Internet. However, a strong research direction and good history of delivering on tasks must first be established as these agencies expect good accountability when entrusted with programme funds.

4. Strong peer review process. Our research findings should be subjected to peer review before publication. The level of peer review and editorial process for publication currently obtainable is poor. This may have implications for our ability to disseminate research results through leading databases and to obtain recognition by journal citation review services. At present, there is no Nigerian journal covered in the Journal Citation Review (JCR) of the ISI web of Knowledge Journal Universe; only a few African journals have made the grade (29 out of 23,000 
journals, which translates to about $0.13 \%$ for the whole of A f r ica) (ht t p://thomsonreuters. com / products_services/scientific/Journal_Citation_Reports). We have to strive to raise publication standards to a level that makes them acceptable for citation in leading databases.

5. Proper dissemination and availability of research reports. Once a research work is completed, the findings ought to be disseminated through the appropriate quarters for accessibility. The birth of another channel for publication of research work in rehabilitation (African Journal of Physiotherapy and Rehabilitation Sciences) in Nigeria is commendable. All these rehabilitation journals in Nigeria need to work hard to make research reports accessible and available either freely online or through the library systems.

6. Use of evidence from research to back our push for change. A systematic review of evidence has been going on for a while in the developed world of rehabilitation. Physical therapists in Nigeria need to start using information available from such reviews to push the agenda for change - be it the effectiveness of therapeutic exercises or the effectiveness of stroke rehabilitation or the cost effectiveness of rehabilitation versus other means of management of condition such as low back pain.

\section{Influencing Policy Direction}

Physical therapists need to initiate and propel the changes they want to see happen. No one will make these changes happen unless we, who are directly concerned step in and take control. Very clear vision and mission statements, strategic direction, operational plans to achieve the strategic goals and measurement of outcome/reassessment are needed for the goal of policy advocacy to be achieved, no matter how we view the profession of physical therapy - as first contact practitioners, or PTs as a doctoring profession, or even $\mathrm{PT}$ in the forefront of disability management or the "go to" profession when it comes to expertise in musculo-skeletal management.

For too many years, the strategic direction may not have been clear enough organizationally. A logic model could be used to depict how initiatives such as policy advocacy would result in a change in the society. Details are available at < http://www.uwex.edu/ces/pdande/ evaluation/evallogicmodel.html $>$

Influencing policy direction is a very difficult job, and doubly so, in an environment riddled with corruption. We may, however, be able to effect this with research. Policy makers need to see the numbers (even consistently so) to be convinced that anyone can be afflicted with stroke and therefore they need to make policies that will improve rehabilitative care for people with disabilities. Professionals have been known to get involved in legislative manoeuvres (Hansen-Turton et al, 2009). Some of the ways that could be adopted to effect legislative and policy change include the following:

- Building strong grassroots awareness about physical therapy. Presently, awareness about the role of physical therapy is very low. We do not need to hide under the cloak of another profession. The role of physical therapy should be made clear and the profession should be distinctly differentiated from other health care professions (Amusat and Ganiyu, 2009; Branding in Physical Therapy, personal communication, May 11). If we do not do this, all our efforts will become good 'advertisement' for other professions which the society already knows.

- Policy, strategic direction and planning. The professional organization of PT may need to create a section devoted to understanding the health care policies and legislative direction of the country. The PTs must make sure that the legislative environment is conducive to achieving their goals of prevention, health promotion and professional recognition

- Building alliances within the physical therapy community, other health care professional communities, policy-makers beyond partisan divides, civic leaders, private sector/industries.

- Lobbying the law and policy makers to make rules and policies conducive for promoting our strategic direction.

\section{CONCLUSION}

Advocacy has a role to play in improving rehabilitative care for people with disability in Nigeria. Physical therapists are at the core of rehabilitative care in Nigeria and hence have to do more to make rehabilitation accessible to people with disability. Research and legislative lobbying will assist in achieving the goal.

\section{Appendix}

Websites and contacts of international organizations working on disability

1. http://www.independentliving.org/

2. http://www.wid.org/ 
3. http://www.independentliving.org/donet/43_disabled_peop les_international.html

4. http://www.gladnet.org/

5. http://www.independentliving.org/donet/718_group_of_peo ple_with_disabilities.html (based in Ibadan)

6. http://www.inclusion.com/

7. http://www.ilresources.com/

8. http://www.ideas.org.au/

9. http://pedanet.virtualactivism.net/ (based in Benin City)

10. http://www.independentliving.org/donet/787_renewed_hop e_foundation_of_the_disabled_people.html(Based in Ondo State)

11. http://www.thecouncil.org/

12. http://www.rexdonald.com/index.html

13. http://www.vsarts.org/

14. http://www.worldaccessibility.com/

\section{References}

Australian Physiotherapy Association (2006) E v i d e n c e regarding therapeutic exercise in physiotherapy: position statement. Viewed May 3, 2009, <http://apa. advsol.com.au/physio_and_health/media/download/2006/E videnceRegardingTheraputicExerciseInPhysiotherapy.pdf>

Hansen-Turton, T., Ritter, A. and Valdez, B. (2009) Developing alliances: how advanced practice nurses became part of the prescription for Pennsylvania. Policy, Politics and Nursing Practice 10, pp.7-15.

Hyland, D. (2002) An exploration of the relationship between patient autonomy and patient advocacy: implication for nursing practice. Nursing Ethics 9, pp.472-482.

Jugessur, T. and Iles, K. (2009) Advocacy in mental health nursing: an integrative review of the literature. Journal of Psychiatric and Mental Health Nursing 16, pp.187-195.

Lang, R. and Upah, L. (2008) Scoping study: Disability issues in Nigeria. Viewed May 3, 2009, < http://www.ucl.ac.uk/lcccr/downloads/dfid_nigeriareport $>$

Malone, D. (2001) Advocacy - the intangible member service. Australian Journal of Physiotherapy 47, pp.3-4.

Michailakis, D. (1997) Government action on disability policy: A global survey. Viewed May 3, 2009, <http://www. independentliving.org/standardrules/UN_Answers/UN.pdf >

Mji, G., MacLachan, M., Melling-Williams, N. and Gcaza, S. (2009) Realizing the rights of disabled people in Africa: an introduction to the special issue. Disability and Rehabilitation 31, pp.1-6.
Mmatli, T.O. (2009) Translating disability-related research into evidence-based advocacy: the role of people with disabilities. Disability and Rehabilitation 31, pp.14-22.

Nigerian with disability decree (1993) Viewed May 3, $2009,<$ http://www. dredf.org/ international/nig1.html>

Parahoo, K. (2000) Barriers to, and facilitators of, research utilization among nurses in Northern Ireland. Journal of Advanced Nursing 31, 89-98.

Poulis, I. (2007) The end of physiotherapy. Australian Journal of Physiotherapy 53, pp.71-72.

Schwartz, L. (2002) Is there an advocate in the house? The role of health care professionals in patient advocacy. Journal of Medical Ethics 28, pp.37-40.

South Africa Integrated National Disability Strategy (1997) White paper. Viewed May 2, 2009, <www.info.gov.za/ whitepapers/1997/disability.htm>

Teasell R et al. (2009) Evidence-based Review of Stroke Rehabilitation. $11^{\text {th }}$ edition. Viewed May 8, 2009, $<$ http://www. ebrsr.com/index.php>

The Guardian (2009). Nigerian amputated in Sierra Leone, devotes life to helping the disabled. April 12, 2009. Viewed May 3, 2009, <http://www.ngrguardiannews. com/sunday_magazine/article05//indexn3_html?pdate $=120$ $409 \&$ ptitle $=$ Nigerian $\% 20$ Amputated $\% 20$ In $\% 20$ Sierra $\% 2$ 0Leone, \%20Devotes\%20Life \%20To\%20Helping\%20The $\% 20$ Disabled $\&$ cpdate $=160409>$

United Nations (1993) UN Standard Rules on the Equalization of Opportunities for People with Disabilities. Viewed May 3, 2009, <http://www.wcpt.org/node/ 29219>

Ward, S.R. (2007) 2007 APTA presidential address. Physical therapy: stories that must be told. Physical Therapy 87, pp.1555-1557.

WCPT (2007) Physical Therapists as Exercise Experts Across the Life Span. Viewed May 3, 2009, <http://www.wcpt.org/ node/29462>

WCPT (1999) Description of Physical Therapy - What is Physical Therapy? Viewed May 1, 2009, < http://www.wcpt.org/node / 29599>

WCPT (1995) Declaration of Principle - Appendix to World Confederation of Physical Therapy Ethical Principles. Viewed April 25, 2009, available at < http://www.wcpt.org/node/29031>

Wheeler, P.M. (2000) Is advocacy at the heart of professional practice? Nursing Standard 14, pp.39-41.

Wolfensohn, J.D. (2003) Poor disabled and shut out. Washington Post, 3 December. 